www.nature.com/pj

\title{
Miniemulsion polymerization based on in situ surfactant formation without high-energy homogenization: effects of organic acid and counter ion
}

\author{
Yi Guo, Victoria L Teo, SR Simon Ting and Per B Zetterlund
}

Miniemulsion polymerization of styrene based on the in situ surfactant-generation technique has been investigated for a range of carboxylic acids and counterions. This technique relies on in situ formation of the surfactant at the oil-water interface and circumvents the use of traditional high-energy mixing (for example, ultrasonication) for generation of the initial miniemulsion. Miniemulsion polymerizations have been conducted successfully using the carboxylic acids lauric acid, palmitic acid and oleic acid, respectively. Coagulation/phase separation was not observed and the number-average particle diameters were $<100 \mathrm{~nm}$. The counterions $\mathrm{K}^{+}, \mathrm{Na}^{+}$and $\mathrm{Li}^{+}$were investigated in combination with five different carboxylic acids (all permutations), revealing that satisfactory miniemulsion formation/stability could only be obtained with $\mathrm{K}^{+}$. Results of miniemulsion polymerizations conducted in the presence of an aqueous-phase radical scavenger were consistent with predominant monomer droplet nucleation. Use of the corresponding preformed surfactants added to the aqueous phase, without high-energy mixing, did not result in sufficiently stable initial (before polymerization) miniemulsions.

Polymer Journal (2012) 44, 375-381; doi:10.1038/pj.2012.7; published online 15 February 2012

Keywords: anionic surfactant; emulsion polymerization; miniemulsion; radical polymerization

\section{INTRODUCTION}

The heterogeneous polymerization technique known as miniemulsion polymerization $^{1}$ is associated with a number of advantages, most notably its applicability to the synthesis of organic/inorganic hybrid and hollow polymeric nanoparticles ${ }^{2-4}$ in the particle diameter range $50-1000 \mathrm{~nm}, 5,6$ as well as for implementation of controlled/living radical polymerization. ${ }^{7-14}$ Miniemulsion polymerization is distinct from the more common emulsion polymerization technique with respect to the mechanism of particle formation. In miniemulsion polymerization, particles are formed via monomer droplet nucleation, whereas in emulsion polymerization, particle formation occurs in the aqueous phase via micellar and/or homogeneous nucleation. This difference has important implications, because it means that in miniemulsion polymerization, there is no requirement for species to diffuse across the aqueous phase from monomer droplets to polymer particles, and hence the synthetic advantages highlighted above. The main drawback of the miniemulsion polymerization technique is that high-energy mixing (for example, ultrasonication or high pressure homogenization) is generally required for formation of the initial thermodynamically unstable emulsion. This requirement has been an impediment to industrial exploitation and it is therefore desirable to develop low-energy methods to conduct miniemulsion polymerization.

A range of low-energy miniemulsification procedures exist. There are numerous reports describing miniemulsification techniques relying on catastrophic phase transitions occurring as a result of a change in temperature (phase inversion temperature method), ${ }^{15,16}$ pressure, ${ }^{17,18} \mathrm{pH},{ }^{19}$ ionic strength ${ }^{20}$ or composition (emulsion inversion point method). ${ }^{21,22}$ However, the application of such miniemulsification techniques to miniemulsion polymerization (as opposed to merely the miniemulsification process itself) has not been extensively investigated. ${ }^{23-26}$

Low-energy miniemulsification can also be achieved by use of the so called in situ surfactant technique. ${ }^{27-30}$ An organic acid dissolved in the organic phase (for example, oleic acid (OA)) reacts at the oil-water interface with a base (for example, potassium hydroxide) in the aqueous phase, thereby generating the surfactant directly at the interface. Surfactant diffusion from the aqueous phase to the interface is 
therefore not required (unlike when preformed surfactant is dissolved in the aqueous phase), and this is believed to be one of the key reasons why high-energy mixing is not required. It has also been demonstrated that surfactant generation at the interface combined with high-energy miniemulsification results in more rapid generation of a given droplet size than with preformed surfactant. ${ }^{31,32}$ Under unsuitable conditions (in terms of ratio of base to acid and amount of surfactant generated), the in situ surfactant technique results in systems that proceed mainly via an emulsion polymerization mechanism. ${ }^{33}$ We have reported that the in situ surfactant technique can also be successfully applied to nitroxide-mediated radical polymerization. ${ }^{29}$ Moreover, we have recently demonstrated that by combination of the in situ surfactant-generation technique and ultrasonication, polymeric nanoparticles of diameters $<20 \mathrm{~nm}$ can be prepared via a miniemulsion polymerization mechanism (using both conventional radical polymerization and nitroxide-mediated radical polymerization) with lower surfactant content than traditionally required in microemulsion polymerizations. $^{34}$

In the present contribution, a number of different carboxylic acids and counterions (bases) have been investigated with respect to their ability to induce in situ surfactant miniemulsion polymerization of styrene (St).

\section{MATERIALS AND METHODS}

\section{Materials}

Styrene (99\%; Sigma-Aldrich, Sydney, New South Wales, Australia) was purified by passing through an aluminium-oxide column (Ajax Finechem, Sydney, New South Wales, Australia) to remove inhibitor. 2, 2'-Azobisisobutyronitrile (AIBN) was purified by recrystallization twice in methanol. Lauric acid (LA, 99\%; Sigma-Aldrich), palmitic acid (PA, 99\%; Sigma-Aldrich), oleic acid (OA, 99.9\%; Ajax Finechem.), stearic acid (SA, 95\%; Sigma-Aldrich), behenic acid (BA, 99.9\%; Sigma-Aldrich), hexadecane (99\%; Sigma-Aldrich), potassium persulfate (KPS, 95\%; Serva Feinbiochemica Gmph \& Co., Sydney, New South Wales, Australia), potassium hydroxide pellets (85\%; Ajax Finechem), sodium hydroxide (85\%; Ajax Finechem), lithium hydroxide $(99.5 \%$, Ajax Finechem) and potassium nitrite (97.5\%, Ajax Chemicals, Sydney, New South Wales, Australia) were used as received.

\section{Preparation of (mini)emulsions}

(Mini)emulsions (both in-situ and preformed approaches) were prepared based on the recipes in Table 1 by dropwise addition of the organic phase to the aqueous phase over at least $5 \mathrm{~min}$ under magnetic stirring at 500 r.p.m. In situ surfactant formation: The organic phase (monomer, carboxylic acid and

Table 1 Recipes for miniemulsion polymerizations (amounts in grams; $70^{\circ} \mathrm{C}$ )

\begin{tabular}{|c|c|c|c|c|c|c|}
\hline Run & Styrene & $\begin{array}{c}\text { Organic } \\
\text { acid }\end{array}$ & Initiator & Hexadecane & $\begin{array}{l}\text { Potassium } \\
\text { hydroxide }\end{array}$ & Water \\
\hline & & $\mathrm{OA}$ & KPS & & & \\
\hline \multirow[t]{2}{*}{1} & 1.05 & 0.168 & 0.02 & 0.074 & 0.082 & 17 \\
\hline & & $\mathrm{OA}$ & AIBN & & & \\
\hline \multirow[t]{2}{*}{2} & 1.05 & 0.168 & 0.01 & 0.074 & 0.082 & 17 \\
\hline & & LA & AIBN & & & \\
\hline \multirow[t]{2}{*}{3} & 1.05 & 0.168 & 0.01 & 0.074 & 0.116 & 17 \\
\hline & & PA & AIBN & & & \\
\hline \multirow[t]{2}{*}{4} & 1.05 & 0.168 & 0.01 & 0.074 & 0.091 & 17 \\
\hline & & SA & AIBN & & & \\
\hline 5 & 1.05 & 0.168 & 0.01 & 0.074 & 0.082 & 17 \\
\hline
\end{tabular}

hexadecane) was mixed with the aqueous phase (water, base) as described above. The initiator was dissolved in the organic phase (AIBN) or the aqueous phase (KPS). The resultant mixtures were left under magnetic stirring for $30 \mathrm{~min}$ at room temperature to allow neutralization reaction between acid and base. Preformed surfactants approach: The surfactants were prepared by addition of the carboxylic acid to an aqueous solution of the base $\left(n_{\mathrm{OH}}: n_{\mathrm{COOH}}=2\right)$ followed by elevation of the temperature to $60^{\circ} \mathrm{C}$ for $15 \mathrm{~min}$. Precipitation was first observed because of poor solubility of the acid in water, but a transparent solution was obtained eventually. The organic phase was added to the aqueous surfactant solution after cooling down to room temperature.

\section{Polymerization}

Approximately $10 \mathrm{ml}$ of the emulsion was transferred to a glass bottle and subsequently sealed with a rubber septum and copper wire. After degassing with nitrogen purge for $30 \mathrm{~min}$, the rubber septum was further sealed with vacuum grease and parafilm. Polymerization was carried out at $70^{\circ} \mathrm{C}$ in an oil bath with magnetic stirring at 500 r.p.m. The final polymer was collected by vacuum drying the emulsion at room temperature, and monomer conversion was determined by gravimetry.

\section{Droplet/particle size}

Monomer droplet and polymer particle sizes were measured using dynamic light scattering (DLS; Malvern Nano-ZS, Malvern, UK) at the backscattering angle of $173^{\circ}$ at $25^{\circ} \mathrm{C}$ using the original (mini)emulsions without dilution. The values given are averages of at least three measurements with an interval of at least $5 \mathrm{~min}$ between each measurement. The (mini)emulsions were measured directly without dilution.

\section{RESULTS AND DISCUSSION}

\section{Effect of organic acid}

Miniemulsions were prepared using in situ surfactant formation (without high-energy mixing) based on potassium hydroxide and the five different organic acids LA $\left(\mathrm{C}_{11} \mathrm{H}_{23} \mathrm{COOH}\right)$, PA $\left(\mathrm{C}_{15} \mathrm{H}_{31} \mathrm{COOH}\right)$, SA $\left(\mathrm{C}_{17} \mathrm{H}_{35} \mathrm{COOH}\right)$, OA $\left(\mathrm{C}_{17} \mathrm{H}_{33} \mathrm{COOH}\right)$ and $\mathrm{BA}$ $\left(\mathrm{C}_{21} \mathrm{H}_{43} \mathrm{COOH}\right)$, respectively, with the ratio $n_{\mathrm{OH}}: n_{\mathrm{COOH}}=2$ in all cases (recipes in Table 1). Opaque (white) emulsions of low viscosity were obtained in all cases, with the exception of BA (10-20 wt\% relative to monomer), which generated a highly viscous mixture. All miniemulsions were stable (no visible phase separation) for at least $2 \mathrm{~h}$. The results of DLS measurements of the initial (before polymerization) monomer droplet-size distributions are compiled in Table 2. In all cases (except BA, which could not be analyzed by DLS), number-average droplet diameters $\left(d_{\mathrm{n}}\right)<100 \mathrm{~nm}$ were obtained, increasing in the order $\mathrm{SA}<\mathrm{PA}<\mathrm{OA}<\mathrm{LA}$. The droplet-size distributions (Figure 1) were monomodal for PA and OA, whereas both LA and, in particular, SA resulted in bimodal distributions. The dropletsize distributions were broad in all cases, with $d_{\mathrm{w}} / d_{\mathrm{n}}$ ranging from 1.35 (OA) to 2.18 (LA). In the case of SA, two distinct droplet populations

Table 2 Monomer droplet-size data for initial emulsions (before polymerization) prepared via in situ surfactant formation (16 wt\% relative to monomer) employing different carboxylic acids with potassium hydroxide $\left(n_{\mathrm{OH}} / n_{\mathrm{COOH}}=2\right)$ based on recipes in Table 1

\begin{tabular}{lcccc}
\hline Surfactant & $\mathrm{d}_{n}(n m)$ & $\mathrm{d}_{w} / \mathrm{d}_{n}$ & $\mathrm{~A}_{\text {surf }}\left(n m^{2}\right)^{\mathrm{a}}$ & $\mathrm{c}_{\text {surf }}(M)^{\mathrm{b}}$ \\
\hline KLA & 74 & 2.18 & 0.08 & 0.0132 \\
KPA & 29 & 1.64 & 0.36 & 0.0011 \\
KOA & 49 & 1.35 & 0.29 & 0.0032 \\
KSA & 27 & 1.93 & 0.37 & 0.0007 \\
\hline
\end{tabular}

${ }^{\mathrm{a}} A_{\text {surf }}$, surface (interfacial) area per surfactant molecule (Equation (1)). ${ }^{\mathrm{b}} \mathrm{C}_{\text {surf }}$, surfactant concentration in aqueous phase (Equation (2)). 

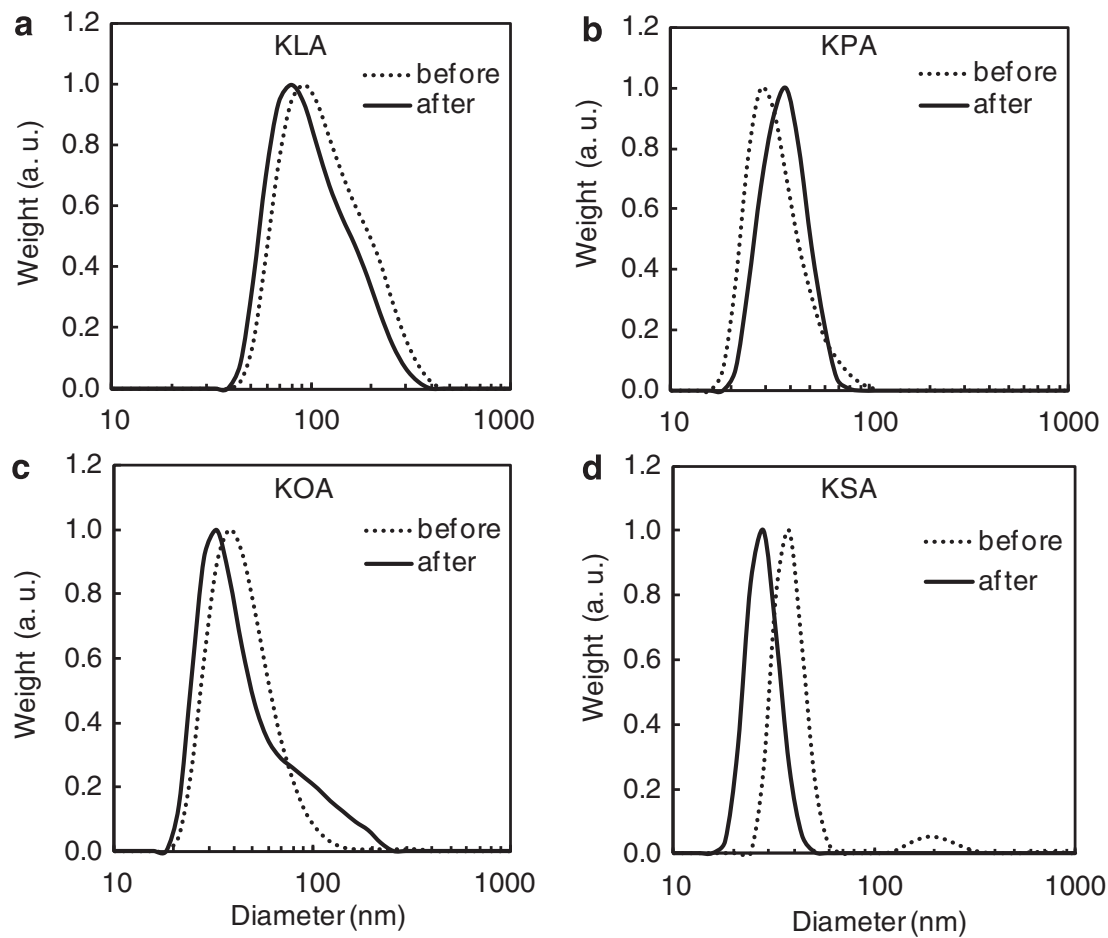

Figure 1 Droplet (before polymerization; dotted lines) and particle-size distributions (after polymerization at $70^{\circ} \mathrm{C}$ for $4 \mathrm{~h}$; full lines) by weight for AIBN-initiated (mini)emulsion polymerizations of styrene at $70^{\circ} \mathrm{C}$ based on in situ surfactant formation of potassium laurate (a), potassium palmitate (b), potassium oleate (c) and potassium stearate (d) (16 wt\% relative to monomer) according to recipes in Table 1.

were observed, with diameters of approximately 25 and $250 \mathrm{~nm}$, respectively.

For comparison, generation of miniemulsions was also attempted using the corresponding preformed surfactants (that is, dissolution of the preformed surfactant, for example, KOA, in the aqueous phase prior to mixing the aqueous and organic phases). Figure 2 shows photographs of initial miniemulsions based on preformed and in situgenerated KOA immediately after preparation as well as after $2 \mathrm{~h}$, revealing how severe phase separation has occurred in $2 \mathrm{~h}$ in the case of preformed KOA, whereas the in situ KOA miniemulsion exhibits no phase separation. Similar results were obtained for the other organic acids investigated. The stabilities of the initial miniemulsions using preformed surfactant were so poor that DLS analysis was not possible.

Polymerizations to high conversion of the above miniemulsions (in situ surfactant generation and preformed surfactant) were carried out at $70^{\circ} \mathrm{C}$ initiated by AIBN, resulting in polymer particles with $d_{\mathrm{n}}<100 \mathrm{~nm}$ in all cases (Table 3 ). In an 'ideal' miniemulsion polymerization, the initial monomer droplets would be converted to polymer particles with preservation of the initial monomer droplet identity. As such, if the present polymerizations proceed according to a miniemulsion polymerization mechanism, the particle-size distribution should resemble the initial monomer droplet distribution. In the case of in situ surfactant generation, the particle-size distributions were quite similar to the initial droplet-size distributions (Figure 1), especially for LA and PA, but also for OA. Particle diameters vs conversion are plotted in Figure 3a for PA, revealing that the diameter increases somewhat with increasing conversion, indicative of some coalescence/Ostwald ripening. In the case of SA, the particle-size distribution is monomodal and comprises much smaller particles than the initial bimodal
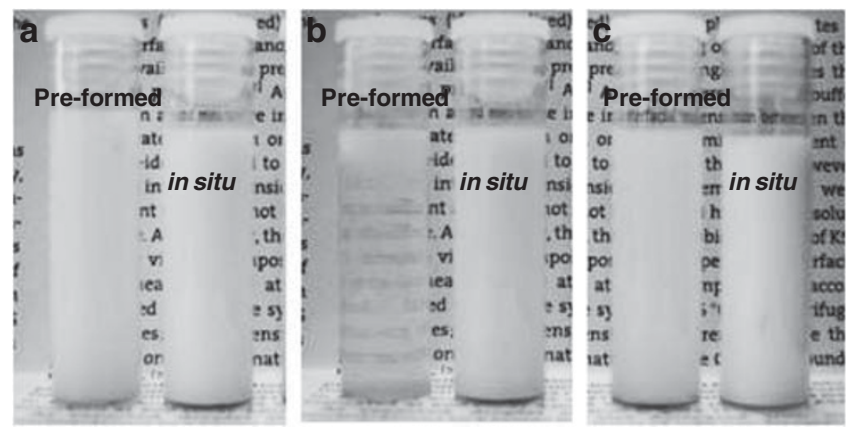

Figure 2 Photographs of miniemulsions (a) immediately after preparation, (b) after left standing for $2 \mathrm{~h}$ after preparation and (c) after polymerization at $70{ }^{\circ} \mathrm{C}$ for $4 \mathrm{~h}$ (using (a)) for miniemulsions prepared using preformed and in situ generated potassium oleate (recipes and conditions in Table 1).

droplet-size distribution, consistent with a predominant emulsion polymerization mechanism.

Employing the preformed surfactants, the emulsions after polymerization exhibited $d_{\mathrm{n}}<100 \mathrm{~nm}$ in all cases despite severe phase separation of the initial emulsions. In these cases, the polymerization mechanism is that of an emulsion polymerization, that is, particle formation occurs in the aqueous phase via micellar (most likely) or homogeneous nucleation with monomer subsequently being supplied to these particles from large monomer droplets. Figure 4 shows the particle-size distributions, revealing a close to monomodal distribution for OA but multimodal distributions for PA and SA.

In the present work, both the initial monomer droplet size and the final particle size (using in situ surfactant technique) increased in the order $\mathrm{SA}<\mathrm{PA}<\mathrm{OA}<\mathrm{LA}$ (Tables 2 and 3 ). Inclusion of $\mathrm{SA}$ in the 
Table 3 Particle-size data for AIBN-initiated (mini)emulsion polymerizations at $70{ }^{\circ} \mathrm{C}$ for $4 \mathrm{~h}$ using in situ surfactant formation and preformed surfactant (16 wt\% relative to monomer) employing different carboxylic acids with potassium hydroxide $\left(n_{\mathrm{OH}} / n_{\mathrm{COOH}}=2\right)$ based on recipes in Table 1

\begin{tabular}{llccc}
\hline \multirow{2}{*}{ Surfactant } & Emulsification & Conversion $(\%)^{\mathrm{a}}$ & $\mathrm{d}_{n}(n \mathrm{~m})$ & $\mathrm{d}_{w} / \mathrm{d}_{n}$ \\
\hline \multirow{2}{*}{ KLA } & In situ & 83 & 73 & 1.43 \\
& Preformed & - & - & - \\
KPA & In situ & 87 & 42 & 1.35 \\
& Preformed & 79 & 92 & 2.62 \\
KOA & In situ & 88 & 55 & 1.59 \\
& Preformed & 81 & 43 & 1.36 \\
KSA & In situ & 78 & 19 & 1.98 \\
& Preformed & 88 & 78 & 3.46
\end{tabular}

Abbreviations: KLA, potassium laurate; KOA, potassium oleate; KPA, potassium palmitate; $\mathrm{KSA}$, potassium stearate.

${ }^{a} 70^{\circ} \mathrm{C}$ for $4 \mathrm{~h}$.
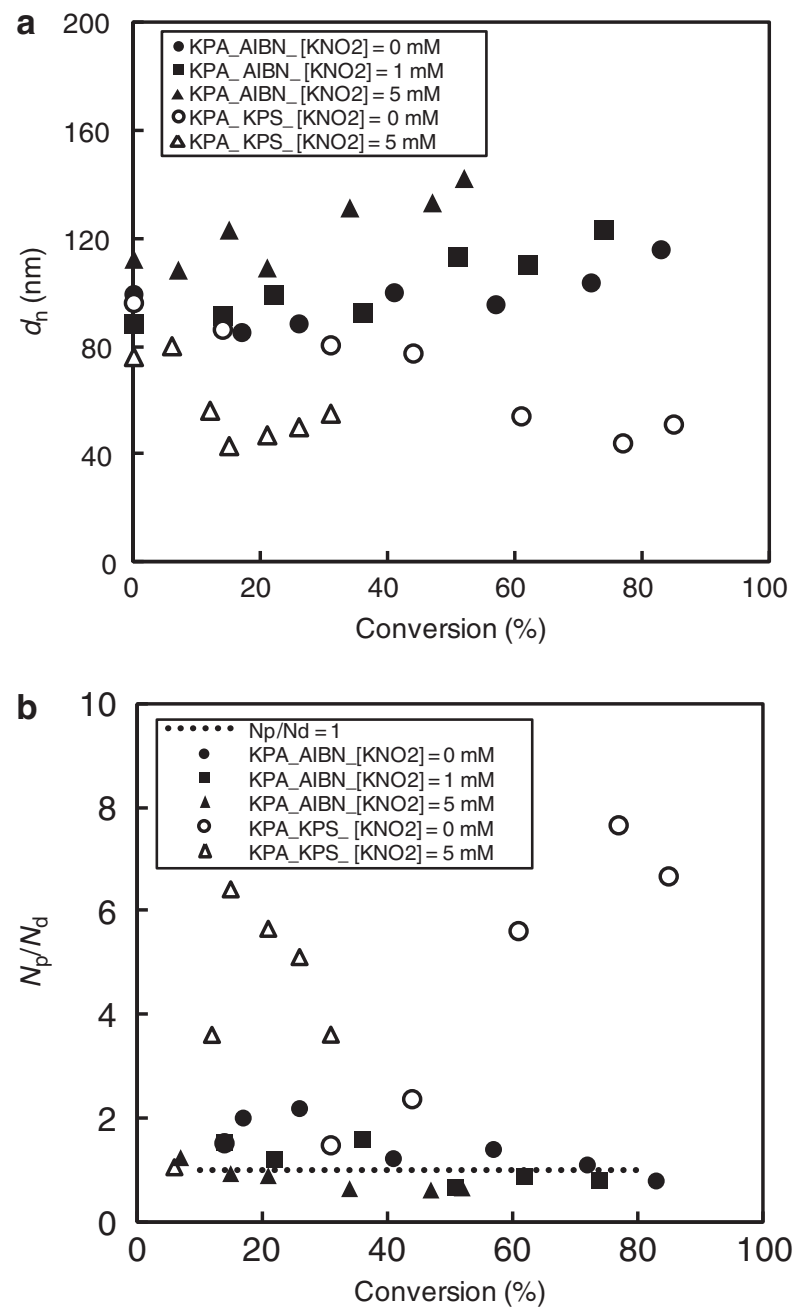

Figure 3 Number-average particle diameters (a) and number of particles relative to initial number of droplets $\left(N_{\mathrm{p}} / N_{\mathrm{d}}\right)$ (b) vs conversion for AIBN(filled symbols) and KPS-initiated (open symbols) miniemulsion polymerization of styrene based on in situ surfactant formation of potassium palmitate at different concentrations of $\mathrm{KNO}_{2}$ (as indicated) at $70^{\circ} \mathrm{C}$ according to recipes in Table 1
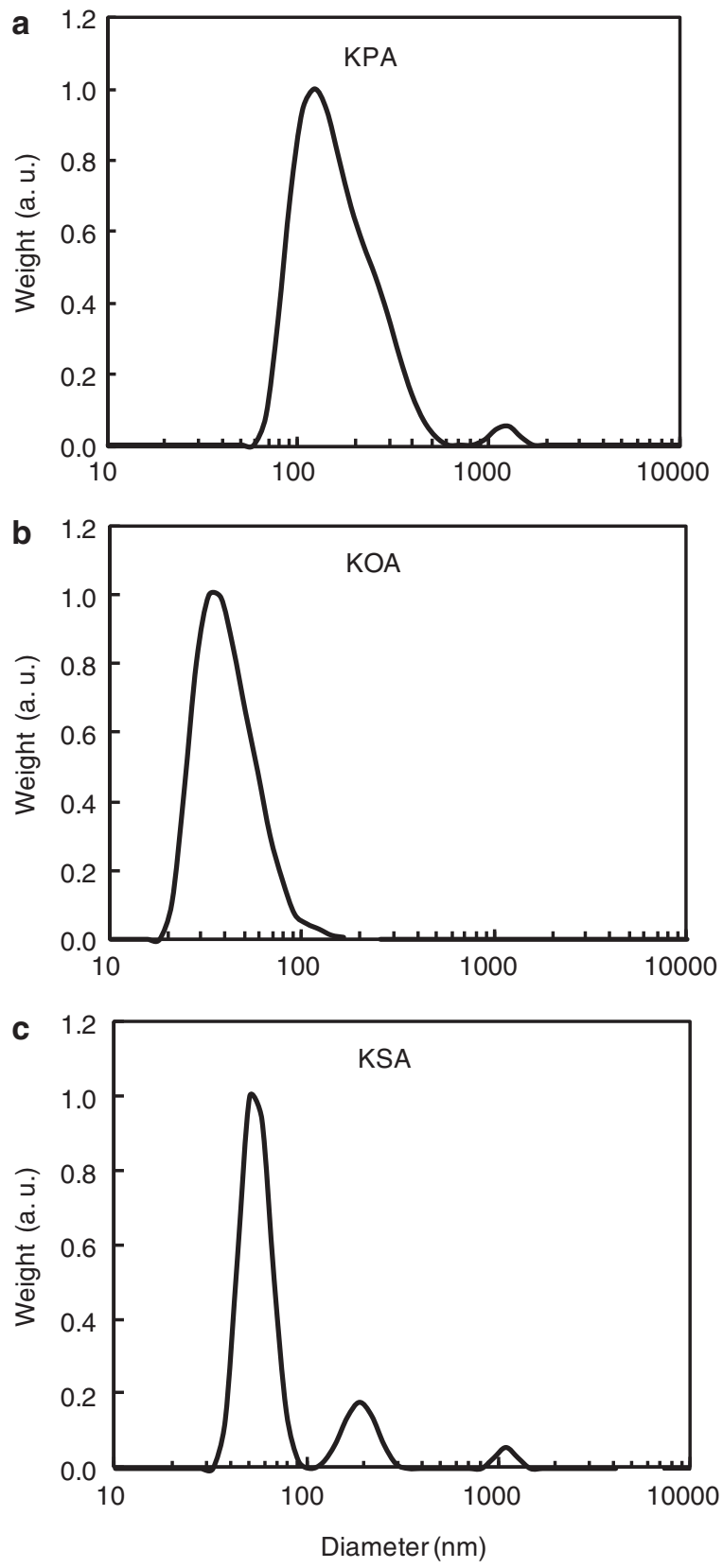

Figure 4 Particle-size distributions by weight for AIBN-initiated (mini)emulsion polymerizations of styrene $\left(70^{\circ} \mathrm{C}, 4 \mathrm{~h}\right.$ ) based on preformed (a) potassium palmitate, (b) potassium oleate and (c) potassium stearate, (16 wt\% relative to monomer) according to recipes in Table 1.

comparison is, however, misleading as in this case, an emulsion polymerization mechanism appears to have been operative (at least partially). The longer the carbon chain of the acid, the lower is the water solubility of the corresponding surfactant, which would be expected to result in a higher surfactant concentration at the oil-water interface and thus smaller droplets/particles. However, there is no clear trend with respect to the number of carbon atoms in the present work. Of course, other factors may well be at play. El-Jaby et al. ${ }^{32}$ reported that in miniemulsion copolymerizations of methyl methacrylate and butyl acrylate employing the in situ surfactant technique (with $\mathrm{KOH}$ ) in tandem with high-energy homogenization, the particle size (after polymerization) increased in the order $\mathrm{LA}<\mathrm{SA}<\mathrm{BA}$. These results 
differ from our results; however, it must be kept in mind that El-Jaby et al. $^{32}$ used high-energy homogenization as well as different monomers. These authors cited possible contributing factors as the influence of carboxylic acid chain length on the hydrophobicity of the monomer phase, as well as the extent of surfactant side reactions. Prokopov and Gritskova ${ }^{27}$ stressed the effect of the water solubility of the surfactant in (mini)emulsion polymerization of styrene based on the in situ surfactant technique. An excessive surfactant concentration in the case of surfactants with high water solubility was reported to yield mixed nucleation modes (monomer droplet nucleation and micellar nucleation) and thus broad particle-size distributions. These authors reported extremely narrow particle-size distributions using in situ-generated KBA (compared with other surfactants generated in situ such as KLA). This is in sharp contrast with our findings, where $\mathrm{BA} / \mathrm{KOH}$ yielded emulsions too viscous to handle. However, the experimental conditions (amount of acid and $n_{\mathrm{OH}} / n_{\mathrm{COOH}}$ ) are not clear in the work of Prokopov and Gritskova, ${ }^{27}$ and further discussion is therefore difficult.

\section{Effect of counterion}

The influence of the nature of the counterion $(\mathrm{KOH}, \mathrm{NaOH}$ and $\mathrm{LiOH}$ ) was investigated for LA, PA, OA and BA with $n_{\mathrm{OH}}: n_{\mathrm{COOH}}=2$ in all cases (basic recipes in Table 1). Of all the possible permutations (all permutations were investigated), the only combination that yielded emulsions with sufficient stability was $\mathrm{KOH}$ with LA, PA and OA. All the other combinations resulted in phase separation, coagulation or extremely viscous mixtures.

El-Jaby et al. ${ }^{32}$ reported that for miniemulsion copolymerizations of methyl methacrylate and butyl acrylate employing the in situ surfactant technique (using SA) in tandem with high-energy homogenization, the initial droplet diameters increased in the order $\mathrm{K}^{+}<\mathrm{Na}^{+}<\mathrm{Li}^{+}$. In all cases, good emulsion stability was observed and the polymerizations proceeded according to a miniemulsion mechanism. These results are in qualitative agreement with our data (note that no high-energy mixing was used in the present work), in the sense that $\mathrm{K}^{+}$was the only counterion that resulted in satisfactory results. As discussed by El-Jaby and coworkers, the hydrated counterion diameters increase in the order $\mathrm{K}^{+}<\mathrm{Na}^{+}<\mathrm{Li}^{+}, 35$ and the smaller diameter of $\mathrm{K}^{+}$is believed to result in a more dense surfactant coverage of the interface, and thus more effective stabilization. Prokopov and Gritskova ${ }^{27}$ also reported that substantially lower interfacial tensions at the styrene/water interface can be obtained using $\mathrm{K}^{+}$(with tetradecanoic acid) than a range of other cations.

\section{Particle-nucleation mechanism}

It is of interest with regards to the particle-nucleation mechanism whether the initial miniemulsions (before polymerization) contain surfactant micelles or not. The monomer droplet surface area per surfactant molecule $\left(A_{\text {surf }}\right)$ of the initial monomer droplets can be estimated based on Equation (1): ${ }^{36}$

$$
A_{\text {surf }}=A_{\mathrm{d}} /\left(N_{\text {surf }} / N_{\mathrm{d}}\right)
$$

where $A_{\mathrm{d}}$ is the surface area per droplet, $N_{\text {surf }}$ is the total number of surfactant molecules assuming complete neutralization of carboxylic acid and $N_{\mathrm{d}}$ is the total number of droplets $\left(N_{\mathrm{d}}=V_{\text {org }} / V_{\mathrm{d}}\right.$, where $V_{\mathrm{d}}$ is the volume per droplet based on $d_{\mathrm{w}}$ and $V_{\text {org }}$ is the total volume of organic phase based on the density of styrene at $\left.25^{\circ} \mathrm{C}\left(0.906 \mathrm{~g} \mathrm{~cm}^{-3}\right)\right)$. The values of $A_{\text {surf }}$ given by Equation (1) are lower limits because the surfactant partitions between the interface and the continuous phase. In the case of the anionic surfactant sodium dodecyl sulfate, $A_{\text {surf }} \approx 0.4 \mathrm{~nm}^{2}$ at maximum surfactant surface coverage, ${ }^{36}$ and consequently $A_{\text {surf }}<0.4 \mathrm{~nm}^{2}$ (as computed from Equation (1)) would indicate that some surfactant is located in the aqueous phase (that is, more than what would be expected based on surfactant partitioning only). It is important to point out that the present calculation is approximate and only serves as an indication as to whether micelles were present or not. The head-group area occupied by the surfactant at the droplet interface would be different for sodium dodecyl sulfate and the surfactants in the present study, and would also be a function of $\mathrm{pH}$ and probably also chain length (that is, differ between KLA, KPA, KOA and KSA). Based on this approximate analysis, all systems investigated exhibited full surface coverage (Table 2).

Because all miniemulsion recipes in Table 2 contain the same ratio of carboxylic acid to monomer, $A_{\text {surf }}$ decreases with increasing particle size. The concentration of surfactant in the aqueous phase $\left(c_{\text {surf }}\right)$ can be estimated using Equation (2):

$$
c_{\text {surf }}=\left(N_{\text {surf }}-\left(N_{\mathrm{d}} A_{\mathrm{d}} / 0.4\right)\right) / V_{\mathrm{H}_{2} \mathrm{O}} N_{\mathrm{A}}
$$

where $V_{\mathrm{H}_{2} \mathrm{O}}$ is the volume of water and $N_{\mathrm{A}}$ is Avogadro's number (' 0.4 ' corresponds to $A_{\text {surf }} \approx 0.4 \mathrm{~nm}^{2}$ at maximum surface coverage). Based on literature values of the critical micelle concentrations, it is likely that micelles existed for KOA and KSA $\left(c_{\text {surf }}>\right.$ critical micelle concentration) but not for KLA and KPA (critical micelle concentration values: $\mathrm{KLA}^{37}: 26 \mathrm{~mm} ; \mathrm{KPA}^{38}: 2.2 \mathrm{~mm}$; $\mathrm{KOA}^{38}: 1.2 \mathrm{~mm}$; and $\mathrm{KSA}^{38}$ : $0.4 \mathrm{mM}$ ). This analysis thus suggests that for the in situ surfactant systems KOA and KSA, micellar nucleation may have been a contributing particle-formation mechanism. As discussed above, the monomer/particle-size distributions for KSA indicated a marked contribution of an emulsion polymerization type mechanism, although in the case of KOA, there are no clear hallmarks of effects of micellar nucleation in the monomer/particle-size distributions. The best preservation of monomer droplet identity during polymerization was obtained for KLA and KPA, consistent with the absence of micelles in these systems.

The miniemulsion recipes employed are based on wt $\%$ (as opposed to $\mathrm{mol} \%$ ) surfactant, and as such the molar amounts of surfactant increase in the order $\mathrm{KSA}<\mathrm{KOA}<\mathrm{KPA}<\mathrm{KLA}$. Thus, if equimolar amounts of surfactants had been employed, the differences between the systems in terms of the presence of micelles or not are likely to have been magnified (for example, increasing the amount of KSA to reach the same molar amount as KLA), thus not altering the present findings.

The particle-nucleation mechanism was also investigated by use of an aqueous phase inhibitor $\left(\mathrm{KNO}_{2}{ }^{39,40}\right)$ in the case of in situ formation of KPA. In a miniemulsion polymerization, particles are formed from monomer droplet nucleation, for example, monomer droplets are converted to polymer particles. In an emulsion polymerization, polymer particles originate from nucleation (micellar or homogeneous) in the aqueous phase, whereas the monomer droplets act merely as monomer reservoirs. Consequently, an emulsion polymerization would be severely retarded/inhibited in the presence of an aqueous-phase inhibitor, whereas a miniemulsion polymerization with an oil-soluble initiator would be much less retarded because aqueous-phase kinetics has a lesser role. The inhibitor $\mathrm{KNO}_{2}$ was chosen over the more commonly used $\mathrm{NaNO}_{2}$ to minimize formation of NaPA (which was shown to behave poorly as surfactant).

AIBN- and KPS-initiated miniemulsion polymerizations of styrene were conducted with different concentrations of $\mathrm{KNO}_{2}$ (same recipes as in Runs 1 and 2 in Table 1). Even in a miniemulsion with $100 \%$ droplet nucleation with an oil-soluble initiator, aqueous-phase kinetics still has a role because initiation events also occur via radical entry into droplets due to the fraction of initiator located in the aqueous 


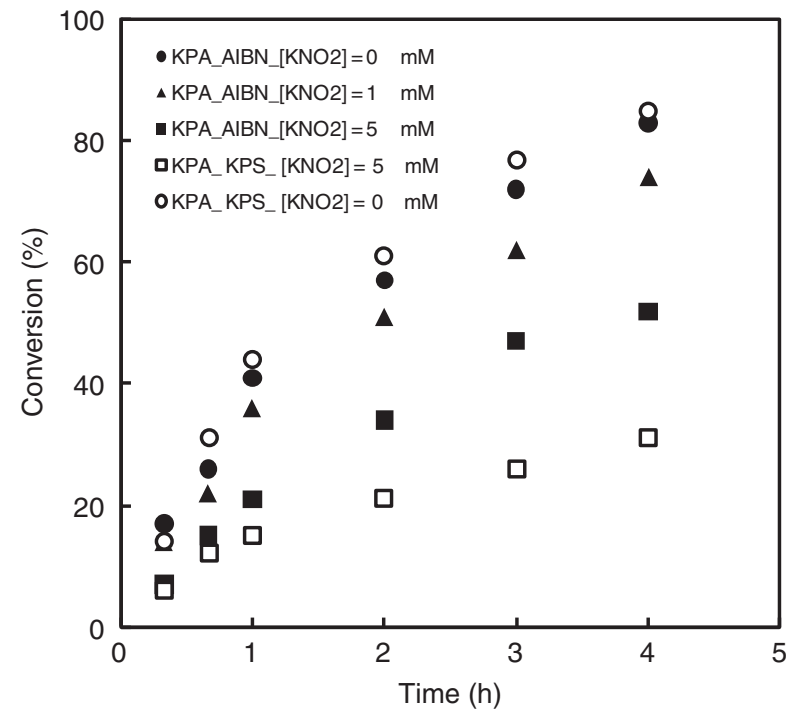

Figure 5 Conversion-time data for AIBN- (filled symbols) and KPS-initiated (open symbols) miniemulsion polymerization of styrene based on in situ surfactant formation of potassium palmitate at different concentrations of $\mathrm{KNO}_{2}$ (as indicated) at $70^{\circ} \mathrm{C}$ according to recipes in Table 1 .

phase, as well as due to exit of initiator radicals from droplets (followed by aqueous-phase termination or re-entry). ${ }^{41-43}$ As such, some retardation would be anticipated in the presence of an aqueousphase radical scavenger even in the case of exclusive droplet nucleation with an oil-phase initiator such as AIBN. The polymerization rate decreased with increasing $\mathrm{KNO}_{2}$ concentration for both initiators, but the decrease was much more significant for KPS (Figure 5). The extent of retardation was relatively mild for AIBN, consistent with significant droplet nucleation.

For AIBN without inhibitor, the particle diameter increased somewhat with increasing conversion as discussed above (Figure 3a). The increase in diameter with conversion becomes more significant with increasing amount of inhibitor. The lower the nucleation rate and the polymerization rate, the more time is available for the miniemulsion to degrade via coalescence, Ostwald ripening and diffusion of monomer from droplets to nucleated droplets (particles), and thus the increase in particle size becomes greater. The fact that the particle size increases with conversion is consistent with a miniemulsion mechanism. However, micellar/homogeneous nucleation occurring to some extent cannot be excluded based on these data only. The nucleation stage in an emulsion polymerization would normally be complete before approximately $10 \%$ conversion, and as such it is possible that even if significant secondary nucleation did occur in the present systems, there may not be a marked decrease in particle size with conversion beyond low conversion. However, the fact remains that in the case of KPS, the continuous decrease in particle size indicates secondary nucleation. The minor increase in particle size at approximately 15 and $75 \%$ conversion, respectively, in the presence of $\mathrm{KNO}_{2}$ is most likely caused by miniemulsion degradation as the polymerization rate is very low due to the inhibitor. Figure $3 \mathrm{~b}$ shows the DLS data plotted as the number of particles (strictly speaking, the number of particles and droplets) relative to the initial number of droplets $\left(N_{\mathrm{p}} / N_{\mathrm{d}}\right.$; based on $\left.d_{\mathrm{w}}\right)$, revealing how the deviation from unity is much more dramatic for KPS than AIBN. The inhibitor data presented above are consistent with previously reported data of aqueous- phase inhibitor effects on the miniemulsion polymerization of styrene based on in situ formation of KOA. ${ }^{30}$

\section{CONCLUSIONS}

Miniemulsion polymerization of styrene utilizing the in situ surfactantgeneration technique without high-energy mixing, whereby the surfactant is generated in situ at the oil-water interface, has been examined for various carboxylic acids and counterions. Miniemulsion polymerizations with satisfactory colloidal stability and numberaverage particle diameters $<100 \mathrm{~nm}$ have been conducted using LA, $\mathrm{PA}$ and OA, respectively. The performances (in terms of miniemulsion stability and droplet/particle size) of the carboxylic acids that yielded miniemulsions with satisfactory stability were similar despite their different water solubilities. The counterions $\mathrm{K}^{+}, \mathrm{Na}^{+}$and $\mathrm{Li}^{+}$ were investigated in combination with all five carboxylic acids (all permutations), but satisfactory miniemulsion formation/stability was only achieved with $\mathrm{K}^{+}$. The particle-formation mechanism was investigated in the case of PA by use of an aqueous-phase radical scavenger, revealing that monomer droplet nucleation is likely to be the predominant nucleation mechanism. Miniemulsion formation was also attempted using the same recipes as for the in situ surfactantgeneration technique, but instead by adding the corresponding preformed surfactant to the aqueous phase. In the absence of highenergy mixing, satisfactory colloidal stability could not be achieved using this technique.

The results further confirm the utility of the in situ surfactantgeneration technique for miniemulsion polymerization in the absence of high-energy homogenization.

\section{ACKNOWLEDGEMENTS}

PBZ is grateful for a Future Fellowship from The Australian Research Council, and strategic funding from The University of New South Wales.

1 Ugelstad, J., El-Aasser, M. S. \& Vanderhoff, J. W. Emulsion polymerization - initiation of polymerization in monomer droplets. J. Polym. Sci. Polym. Lett. 11, 503 (1973).

2 Landfester, K. Miniemulsion polymerization and the structure of polymer and hybrid nanoparticles. Ang. Chem. Int. Ed. 48, 4488 (2009)

3 Faucheu, J., Gauthier, C., Chazeau, L., Cavaille, J. Y., Mellon, V. \& Lami, E. B. Miniemulsion polymerization for synthesis of structured clay/polymer nanocomposites: Short review and recent advances. Polymer 51, 6 (2010).

4 van Berkel, K. Y. \& Hawker, C. J. Tailored composite polymer-metal nanoparticles by miniemulsion polymerization and thiol-ene functionalization. J. Polym. Sci.; Part A: Polym. Chem. 48, 1594 (2010).

5 Asua, J. M. Miniemulsion polymerization. Prog. Polym. Sci. 27, 1283 (2002).

6 Landfester, K. Polyreactions in miniemulsions. Macromol. Rapid Commun. 22, 896 (2001).

7 Zetterlund, P. B., Kagawa, Y. \& Okubo, M. Controlled/living radical polymerization in dispersed systems. Chem. Rev. 108, 3747 (2008).

8 Cunningham, M. F. Controlled/living radical polymerization in aqeuous dispersed systems. Prog. Polym. Sci. 33, 365 (2008).

9 Pan, G., Sudol, E. D., Dimonie, V. L. \& El-Aasser, M. S. Surfactant concentration effects on nitroxide-mediated living free radical miniemulsion polymerization of styrene. Macromolecules 35, 6915 (2002).

10 Farcet, C., Nicolas, J. \& Charleux, B. Kinetic study of the nitroxide-mediated controlled free-radical polymerization of nBA in aqueous miniemulsions. J. Polym. Sci. Part A: Polym. Chem. 40, 4410 (2002).

11 Alam, M. N., Zetterlund, P. B. \& Okubo, M. Network formation in nitroxide-mediated radical copolymerization of styrene and divinylbenzene in miniemulsion. Macromol. Chem. Phys. 207, 1732 (2006).

12 Saka, Y., Zetterlund, P. B. \& Okubo, M. Gel formation and primary chain lengths in nitroxide-mediated radical copolymerization of styrene and divinylbenzene in miniemulsion. Polymer 48, 1229 (2007).

13 Zetterlund, P. B., Nakamura, T. \& Okubo, M. Mechanistic investigation of particle size effects in TEMPO-mediated radical polymerization of styrene in aqueous miniemulsion. Macromolecules 40, 8663 (2007). 
14 Simms, R. W. \& Cunningham, M. F. High molecular weight poly(butyl methacrylate) by reverse atom transfer radical polymerization in miniemulsion initiated by a redox system. Macromolecules 40, 860 (2007).

15 Fernandez, P., André, V., Rieger, J. \& Kühnle, A. Nano-emulsion formation by emulsion phase inversion. Colloids Surf A 251, 53 (2004).

16 Morales, D., Gutierrez, J. M., Garcia-Celma, M. J. \& Solans, Y. C. A study of the relation between bicontinuous microemulsions and oil/water nano-emulsion formation. Langmuir 19, 7196 (2003).

17 Zhang, J., Han, B., Zhang, C., Li, W. \& Feng, X. Nanoemulsions induced by compressed gases. Angew. Chem. Int. Ed. 47, 3012 (2008).

18 Zhao, Y., Zhang, J., Li, W., Zhang, C. \& Han, B. Synthesis of uniform hollow silica spheres with ordered mesoporous shells in a $\mathrm{CO} 2$ induced nanoemulsion. Chem. Commun. 2365 (2009).

19 Salager, J. L. in: Encyclopedia of Emulsion Technology Vol. 3 (Marcel Dekker), New York, 1988.

20 Lamaallam, S., Bataller, H., Dicharry, C. \& Lachaise, J. Formation and stability of miniemulsions produced by dispersion of water/oil/surfactants concentrates in a large amount of water. Colloid Surf A: Physicochem. Eng. Asp. 270, 44 (2005).

21 Sole, I., Maestro, A., Gonzalez, C., Solans, C. \& Gutierrez, J. M. Optimization of nano-emulsion preparation by low-energy methods in an ionic surfactant system. Langmuir 22, 8326 (2006).

22 Wang, L., Mutch, K. J., Eastoe, J., Heenan, R. K. \& Dong, J. Nanoemulsions prepared by a two-step low-energy process. Langmuir 24, 6092 (2008).

23 Spernath, L. \& Magdassi, S. A new method for preparation of poly-lauryl acrylate nanoparticles from nanoemulsions obtained by the phase inversion temperature process. Polym. Adv. Techn. 18, 705 (2007).

24 Spernath, L., Regev, O., Levi-Kalisman, Y. \& Magdassi, S. Phase transitions in O/W lauryl acrylate emulsions during phase inversion, studied by light microscopy and cryoTEM. Colloids Surf. A 332, 19 (2009).

25 Cheng, S. Q., Guo, Y. \& Zetterlund, P. B. Miniemulsion polymerization based on low energy emulsification with preservation of initial droplet identity. Macromolecules 43, 7905 (2010).

26 Sadtler, V., Rondon-Gonzalez, M., Acrement, A., Choplin, L. \& Marie, E. PEO-covered nanoparticles by emulsion inversion point (EIP) method. Macromol. Rapid Commun. 31, 998 (2010).

27 Prokopov, N. I. \& Gritskova, I. A. Characteristic features of heterophase polymerization of styrene with simultaneous formation of surfactants at the interface. Russ. Chem. Rev. 70, 791 (2001).

28 Parker, D. K., Feher, F. J. \& Mahadevan, V. Controlled Polymerization. (US Patent 6992156 Jan 31, 2006 2006).
29 Guo, Y., Liu, J. Q. \& Zetterlund, P. B. Nitroxide-mediated radical polymerization in miniemulsion on the basis of in situ surfactant formation without use of homogenization device. Macromolecules 43, 5914 (2010).

30 Guo, Y. \& Zetterlund, P. B. Particle formation mechanism in radical polymerization in miniemulsion based on in situ surfactant formation without high energy homogenization. Polymer 52, 4199-4207 (2011).

31 El-Jaby, U., Cunningham, M. \& McKenna, T. F. L. The advantages of in situ surfactant generation for miniemulsions. Macromol. Rapid Commun. 31, 558 (2010).

32 El-Jaby, U., Cunningham, M. \& McKenna, T. F. L. Miniemulsions via in situ surfactant generation. Macromol. Chem. Phys. 211, 1377 (2010).

33 Saygi-Arslan, O., Sudol, E. D., Daniels, E. S., El-Aasser, M. S. \& Klein, A. In situ surfactant generation as a means of miniemulsification? J. Appl. Polym. Sci. 111, 735 (2009).

34 Guo, Y. \& Zetterlund, P. B. Synthesis of nano-sized $(<20 \mathrm{~nm})$ polymer particles by radical polymerization in miniemulsion employing in situ surfactant formation. Macromol. Rapid Commun 32, 1669-75 (2011).

35 Volkov, A. G., Paula, S. \& Deamer, D. W. Two mechanisms of permeation of small neutral molecules and hydrated ions across phospholipid bilayers. Bioelectrochem. bioenerg. 42, 153 (1997).

36 Landfester, K., Bechthold, N., Tiarks, F. \& Antonietti, M. Formulation and stability mechanisms of polymerizable miniemulsions. Macromolecules 32, 5222 (1999).

37 Mukerjee, P. \& Mysels, K. J. Critical micelle Concentration of Aqueous Surfactant Systems (National Bureau of standards: Washington DC, 1971).

38 Constantinides, P. P. \& Steim, J. M. Physical properties of fatty acyl-coa - Critical micelle concentrations and micellar size and shape. J. Biolog. Chem. 260, 7573 (1985).

39 Capek, I. On the role of oil-soluble initiators in the radical polymerization of micellar systems. Adv. Colloid Interf. Sci. 91, 295 (2001).

40 Luo, Y. \& Schork, F. J. Emulsion and miniemulsion polymerizations with an oil-soluble initiator in the presence and absence of an aqueous-phase radical scavenger. J. Polym. Sci.; Part A: Polym. Chem. 40, 3200 (2002).

41 Nomura, M., Ikoma, J. \& Fujita, K. Kinetics and mechanisms of emulsion polymerization initiated by oil-soluble initiators .4. Kinetic modeling of unseeded emulsion polymerization of styrene initiated by $2,2^{\prime}$-azobisisobutyronitrile. J. Polym. Sci.; Part A: Polym. Chem. 31, 2103 (1993).

42 Autran, C., de-la-Cal, J. C. \& Asua, J. M. (Mini)emulsion polymerization kinetics using oil-soluble initiators. Macromolecules 40, 6233 (2007).

43 Reimers, J. \& Schork, F. J. Robust nucleation in polymer-stabilized miniemulsion polymerization. J. Appl. Polym. Sci. 59, 1833 (1996). 